\title{
Guest editors’ preface
}

\author{
Francisco M. Fernandes ${ }^{1}$ and Bernd Wicklein ${ }^{2, *}$ \\ ${ }^{1}$ Laboratoire de Chimie de la Matière Condensée de Paris (LCMCP), Université Pierre et Marie Curie, Sorbonne Universités, \\ UMR7574, 4 Place Jussieu, 75252 Paris, France \\ ${ }^{2}$ Instituto de Ciencia de Materiales de Madrid, CSIC, c/Sor Juana Ines de la Cruz 3, 28049 Madrid, Spain
}

Received: 13 June 2017
Published online:
28 June 2017
C Springer Science+Business
Media, LLC 2017

Macroporous materials are pervasive in nature as well as in numerous technical and scientific fields. Just as the rise of micro- and nanotechnologies in the last decades has led to an ever-growing attention to small-sized systems, the same trend has occurred in porous materials research. Driven by energy and catalysis applications, the scientific landscape of porous media has been dominated by microporous and mesoporous materials. However, inspired not only by the macroporous structure of some biological materials like bone or wood, but also by their mechanical performance, enhanced diffusion and insulating properties, macroporous materials have regained attention during the last decade. In addition, the rise of new processing techniques such as 3D printing, stereolithography or ice templating, have brought about significant advances to the field in terms of morphological control and scalability.

The present special collection of ten papers, including three review articles, in the Journal of
Materials Science highlights recent advances in macroporous materials. It follows the organization of the first International Symposium on Macroporous Materials: From Novel Preparation Techniques to Advanced Applications with more than 60 participants. This event, jointly organized by the guest editors, was held in Paris in September 2016 (Fig. 1). It focused on the recent advances in the synthesis, characterization and application of macroporous materials. The goal of the symposium and the resultant collection of papers is to gather contributions from different domains working on novel approaches to macroporous materials and to promote an interdisciplinary debate around this class of materials. The diversity of applications is well illustrated, for instance, by the contributions of Zhang et al. focusing on hydrogen generation from macroporous $\mathrm{ZnO} / \mathrm{ZnS} / \mathrm{CdS}$ photocatalytic composite spheres [1] and the two contributions of Coquard and Baillis, where the thermal conductivity of cellular foams is analyzed by

Address correspondence to E-mail: bernd@icmm.csic.es 


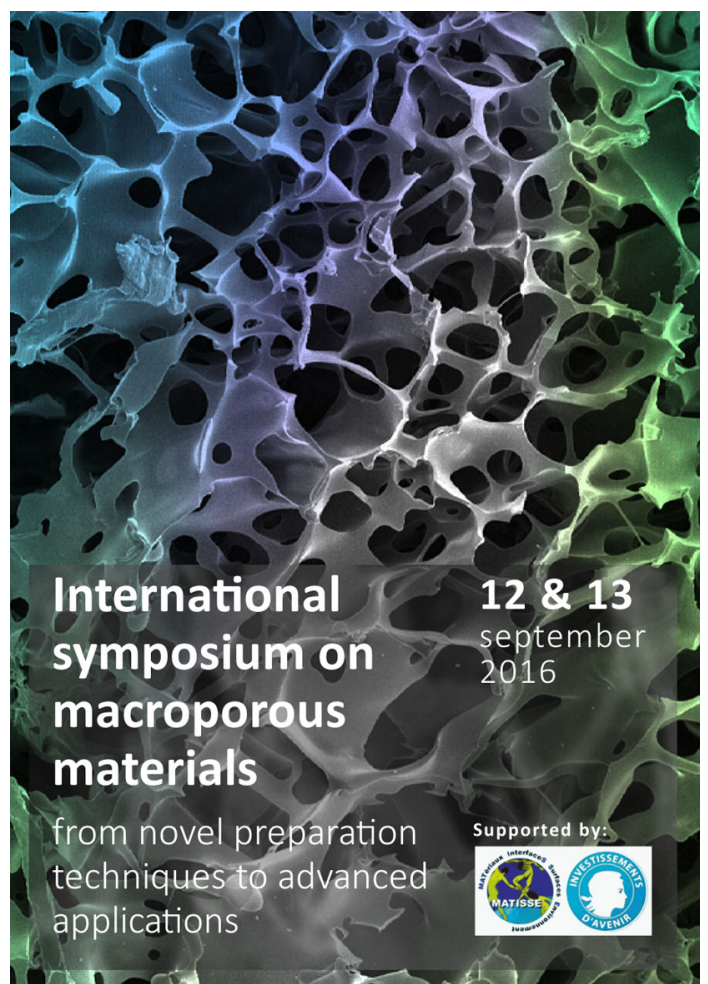

Figure 1 Promotional image for the International Symposium on Macroporous Materials held on September 12-13, 2016, at the Université Pierre et Marie Curie.

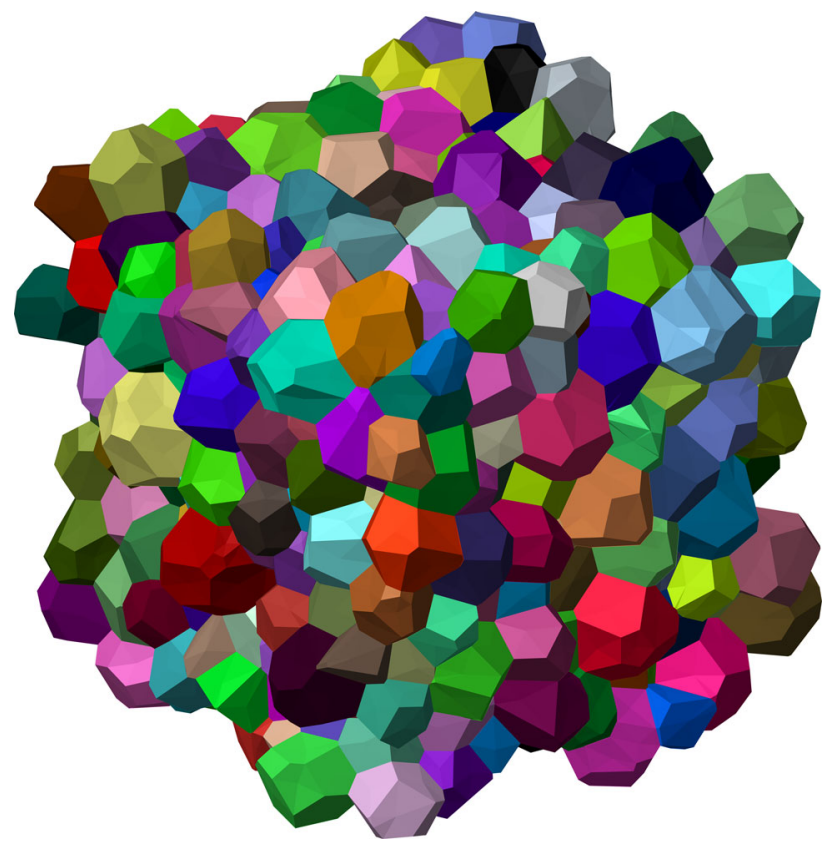

Figure 2 Voronoi tessellation representing cellular materials. Courtesy of Prof. D. Baillis, Institut National des Sciences Appliquées de Lyon. theoretical methods (Fig. 2) [2, 3]. Also the materials processing techniques discussed in the present collection span a multitude of approaches as diverse as the cold isostatic pressing of alumina powder rendering hierarchical and strong macroporous-mesoporous alumina green bodies as presented by Kocjan et al. [4] or the use of melt-shear organization to make hybrid core/shell particles for the creation of inverse opals, as discussed by Vowinkel et al. [5].

The papers selected for this special collection are illustrative for the ever-growing diversity in the community of macroporous materials and underline the potential for new and exciting scientific opportunities in energy, optical, or biomedical applications.

We would like to express our gratitude to all the authors for their effort and contributions to this special section.

\section{Acknowledgements}

The authors would like to acknowledge the French state funds managed by the ANR within the Investissements $\mathrm{d}$ 'Avenir program under reference ANR-11-IDEX-0004-02, specifically within the framework of the Cluster of Excellence MATISSE, for the financial support of the International Symposium on Macroporous Materials: From Novel Preparation Techniques to Advanced Applications. We would also like to thank Dr. Christopher Blanford, Deputy Editor-in-Chief of the Journal of Materials Science, for his kind assistance in the handling of these papers in this themed collection.

\section{References}

[1] Zhang RL, Xie JW, Wang C, Liu J, Zheng XF, Li Y, Yang XY, Wang HE, Su BL (2017) Macroporous $\mathrm{ZnO} / \mathrm{ZnS} / \mathrm{CdS}$ composite spheres as efficient and stable photocatalysts for solardriven hydrogen generation. J Mater Sci. doi:10.1007/s10853017-1130-6

[2] Coquard R, Baillis D (2017) Thermal conductivity of Kelvin cell cellulosic aerogels: analytical and Monte Carlo approaches. J Mater Sci. doi:10.1007/s10853-017-0982-0

[3] Baillis D, Coquard R, Cunsolo S (2017) Effective conductivity of Voronoi's closed- and open-cell foams: analytical laws and numerical results. J Mater Sci. doi:10.1007/s10853-017$1226-\mathrm{Z}$ 
[4] Kocjan A, Konegger T, Dakskobler A (2017) Hierarchical macroporous-mesoporous $\gamma$-alumina monolithic green bodies with high strength. J Mater Sci. doi:10.1007/s10853-0170894-z
[5] Vowinkel S, Malz F, Rode K, Gallei G (2017) Single-source macroporous hybrid materials by melt-shear organization of core-shell particles. J Mater Sci. doi:10.1007/s10853-0170891-2 